\title{
Anything, anywhere, anytime? Developing indicators to assess the spatial and temporal fragmentation of activities
}

\author{
Bayarma Alexander \\ Urban Land Use and Transportation Center (ULTRANS), Institute of Transportation Studies, \\ University of California, Davis, One Shields Avenue Davis, CA 95616, USA; \\ e-mail: baleksandr@ucdavis.edu
}

\section{Christa Hubers}

Centre for Transport and Society, Department of Planning and Architecture, University of the West of England, Frenchay Campus, Coldharbour Lane, Bristol BS16 1QY, UK;

e-mail: christa.hubers@uwe.ac.uk

\section{Tim Schwanen}

Transport Studies Unit, School of Geography and the Environment, Oxford University Centre for the Environment, University of Oxford, South Parks Road, Oxford OX1 3QY, England; e-mail:tim.schwanen@ouce.ox.ac.uk

\section{Martin Dijst, Dick Ettema}

Department of Human Geography and Planning, Faculty of Geosciences, Utrecht University, PO Box 80115, Utrecht 3508 TC, The Netherlands; e-mail: m.dijst@geo.uu.nl, d.ettema@geo.uu.nl Received 4 August 2010

\begin{abstract}
Developments in transportation and information and communication technologies (ICTs) have facilitated the process labeled activity fragmentation. In this process, the weakened associations between activity, time, and place that ICTs made possible facilitate the disintegration of activities into smaller subtasks, which can then be performed at different times and at different locations. However, until now discussion of the fragmentation of activity hypothesis has been limited to the theoretical domain and largely absent from the empirical domain. In the study reported here we connect both domains by (1) developing a set of measures of activity fragmentation and (2) applying them to study the fragmentation of the activity of paid work using combined activity, travel, and communication diary data collected in the Netherlands in 2007 in order to assess the performance of these indicators. The results show that the indicators differentiate between the multiple facets of activity fragmentation (such as the number, dispersion, and configuration of fragments). The preliminary analyses also suggest that, although the temporal fragmentation of activities appears to be or to have become more common, spatial activity fragmentation is rather limited.
\end{abstract}

\section{Introduction}

Recent technological developments in transportation and information and communication technologies (ICTs) have been hypothesized to enable a fragmentation of activities in both space and time (Couclelis, 2000; 2004). The fragmentation-of-activity hypothesis states that ICTs have weakened the associations between activity, place, and time, thereby facilitating the disintegration of activities into smaller sets of acts that can then be performed at different times, different locations, or both. As a result of this decoupling of activity and place, an individual's opportunities to undertake activities are said to increase significantly, supposedly altering the postindustrial society from place based to person based (Castells, 1996; Couclelis, 1998; Haythornthwaite and Wellman, 2002). Instead of the place dictating the activities that can be performed there, individuals are increasingly free to decide for themselves where and when to engage in activities.

Since most traditional land-use and transportation planning is built on a placebased view of society, the shift to a person-based view exemplified by the fragmentation of activities could have great consequences for urban society (Couclelis, 1998). 
The fragmentation of activity - travel patterns might reveal itself in a changing use of places (eg teleworking or e-shopping from home), travel time (utility of which might be increased by, say, working on a laptop while traveling), and more diversified activity and trip chains (with paid work, caregiving, and leisure activities alternating throughout the day, replacing the traditional nine-to-five paid-work pattern). Activity fragmentation has, furthermore, been predicted to result in increased travel demand and, although traffic during conventional peak hours might be relieved, increased road congestion during what are now considered nonpeak hours might ensue. More dynamic and fragmented activity - travel patterns may reflect changes in people's preferences resulting, for example, in new requirements for dwellings (with preferences possibly changing from living near the main employment location to living close to recreational facilities), workplaces (with flexible workstations), and public transportation (with broadband wireless Internet access in both train stations and the trains themselves). Planners and designers would then have to respond to these changes when designing new buildings and infrastructures.

Although the activity-fragmentation hypothesis is intuitively sensible, it is difficult to grasp empirically. Some attempts have been made to collect empirical evidence for the notion of activity fragmentation (eg, Lenz and Nobis, 2007), but a clear framework for its measurement is still lacking. The aim of this study is, therefore, to develop a set of straightforward, user-friendly measures of activity fragmentation, and to assess their performance. Although this set of indicators could, in principle, be applied to study the fragmentation of any type of activity, we confine our examination to the fragmentation of paid work. Paid work is an activity with the potential to become more person based than place based since ICTs enable workers to extend or redistribute their paid-work activities to previously unconventional parts of the day (early morning, late evening, or weekends) as well as unconventional work locations (eg the home, train, car). On the basis of previous research on the structure and content of total activity patterns (Ettema et al, 2007; Golob, 1998; Hanson, 1982; Lu and Pas, 1999; Pas, 1984) and individuals' ICT usage, we can distinguish certain subgroups of the workforce who could be expected to have more fragmented paidwork patterns than others. Full-time workers, for example, tend to have both spatially and temporally more diversified paid-work patterns than part-time workers. Similarly, the activity patterns of telecommuters have been shown to differ from those of stationary workers (Pendyala et al, 1991; Saxena and Mokhtarian, 1997). Our indicators could be considered satisfactory if they produce different results for different subgroups classified according to their ICT, employment, and sociodemographic characteristics, such that findings of theoretical and empirical studies reported in the literature are confirmed. Consequently, the indicators have been applied to combined activity, travel, and communication diary data collected in the Netherlands in 2007.

In section 2 we describe the definition of activity fragmentation on which our research is based, and follow this with a short description of the three dimensions of fragmentation that we distinguish. In section 3 we present the measures of fragmentation and in section 4 we describe briefly the dataset that formed the basis of our analyses. These are described fully in section 5; the results of the analyses are tabulated according to groups of sociodemographic, ICT, and work-related variables. We conclude with a discussion of the main findings and some suggestions for future research. 


\section{Theoretical notions and the dimensions of activity fragmentation}

\subsection{The concept of activity fragmentation}

The concept of activity fragmentation that underlies this study is inspired by Couclelis (2003) who states that:

"Fragmentation is a process whereby a certain activity is divided into several smaller

pieces, which are performed at different times and/or locations" (page 11).

We distinguish between two types of activity fragmentation: temporal fragmentation (episodes of an activity carried out at different times) and spatial fragmentation (episodes carried out at different locations). It is important to note that an activity consists of smaller subtasks, each of which can consist of several smaller episodes that can be performed at different locations. In general terms, a subtask can be defined as a bundle of actions in the material world undertaken to fulfill an arbitrarily specified goal; we use the term episode to denote a continuous timespan devoted to a particular subtask. Examples of subtasks of paid work can include attending a meeting about a given issue, reading a particular item or browsing the Internet for information about a particular topic. Each of these subtasks can comprise multiple episodes. For instance, a person may browse the Internet for information about a given topic at his or her (primary) workplace in the morning, during the work-to-home commute, and from home in the evening.

A crucial question when studying the fragmentation of activities is how to define an activity, a subtask, or both. This is all the more important as some subtasks lend themselves better than others to performance at unconventional times and places. As Couclelis (2004, page 48) notes about the tasks that constitute the activity of shopping, "[s]ome (notably, paying for the purchase) can only involve one location per purchase while others may involve several locations (eg gathering information, searching, comparing prices)." How an activity or a subtask is defined depends on the research question at hand. If the purpose is to find out whether female telecommuters' paid work is more often alternated with household activities than that of male telecommuters, a more general classification of paid and maintenance activities will suffice. However, if one attempts to determine whether a secretary's paid work is more or less fragmented than that of a college professor, one needs more detailed information on the subtasks that can be distinguished for both professions and the extent to which it is feasible to fragment them spatially and/or temporally.

Furthermore, there are some concepts that are intimately associated with the concept of activity fragmentation but should be distinguished from it: multitasking and spatial diversification. With temporal activity fragmentation, the emphasis is on how a single activity is performed multiple times. Multitasking on the other hand concerns how, at a single moment in time, multiple types of activity are performed more or less simultaneously and largely has to do with the fragmentation of time below the level of temporal resolution of the data. Thus, the basic assumptions behind fragmentation and multitasking are different. Although activity fragmentation is also closely aligned with the notion of spatial diversification put forward by Hanson (1980; see also Hanson and Huff, 1988; Huff and Hanson, 1986), the concepts are used to address different questions. By looking at the variability in the locations people visit for a certain activity during a five-week period, Hanson aimed to establish whether it was appropriate to use only one-day or two-day activity diaries to study people's activity schedules, since these schedules might be highly variable in the longer run (eg week, month). However, the spatial diversification concept ignores the possible division of these broader activities into smaller subtasks and the ICT-enabled spatial and temporal relocation of these tasks. For our purposes, the importance of spatial diversification lies in its emphasis on the level of repetition and variability in an individual's daily behavior. So not only can episodes of a certain activity be relocated over the day, but this relocation can also 
appear to be more or less routinized when viewed over a longer period in that the same fragmented activity pattern might repeat itself every week. For the sake of brevity, the relationships between the concepts of multitasking and spatial diversification and activity fragmentation are left to future studies.

Another field of research that bears resemblance to the investigation of activity fragmentation is the work done on describing the spatial dispersion of human activities using models stemming from physics or ecological sciences (eg González et al, 2008). Basically, González et al aim to establish models and regularities that describe patterns of human activity on an aggregate level. While some of their applied metrics are similar to the metrics employed, is a fundamental difference between the approaches. González et al were concerned with aggregate patterns of all human activities. In fact, their approach deals with geographic data about locations, ignoring the functional characteristics of activities and places. Our work on fragmentation aims to provide individual-level measures of activity fragmentation for specific activities, which are inherently linked to the locations and their functionalities available to an individual.

\subsection{Dimensions of fragmentation}

The definition of fragmentation given above provides a first idea of what the concept entails. The definition does not, however, provide a clear indication of when a certain activity can be considered to be fragmented. This can be assessed using the three dimensions given below. They were derived from the field of ecology, which has a vast literature on the fragmentation of forests (Rutledge, 2003); the dimensions were first applied in activity research by Hubers and colleagues (Hubers et al, 2008).

\subsubsection{Number of fragments}

In ecology, three basic dimensions of fragmentation are usually discerned. The first is the number of fragments an activity is divided into. As Rutledge (2003, page 7) explains: "A plate that is broken into 100 pieces is more fragmented than a plate broken into 10 pieces." For example, if we look at the images under the heading of number of activity episodes in figures 1 and 2, the left-hand images (with only three episodes or locations) can be considered less fragmented than the right-hand images (with six episodes or locations at which the activity or subtask is performed). Let us suppose the plate resembles paid labor: if it is made up of more activity episodes that are performed at more different locations, it is more fragmented.

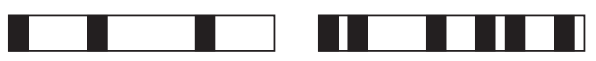

Distribution of sizes
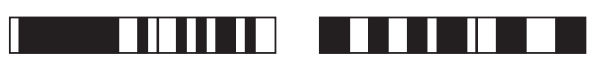

Configuration

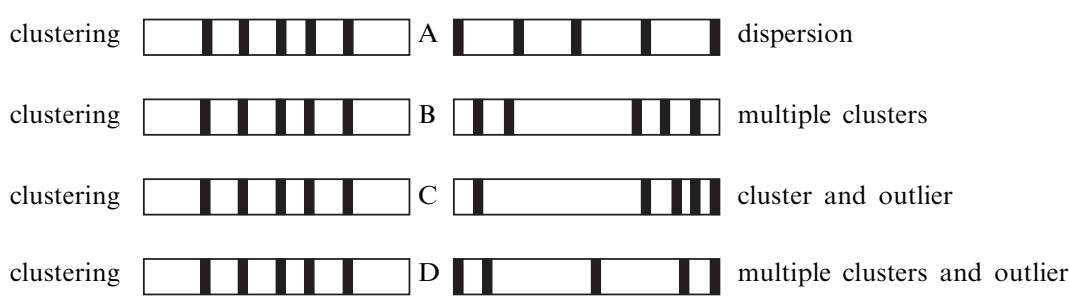

Figure 1. Dimensions of temporal fragmentation. 
less fragmented Number of activity episodes more fragmented

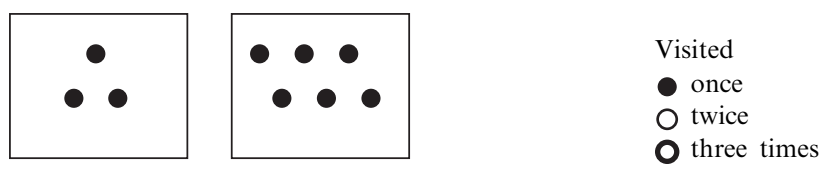

Distribution of sizes

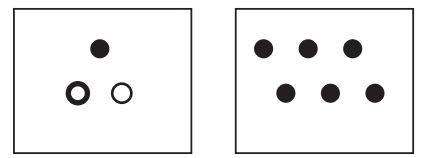

Configuration
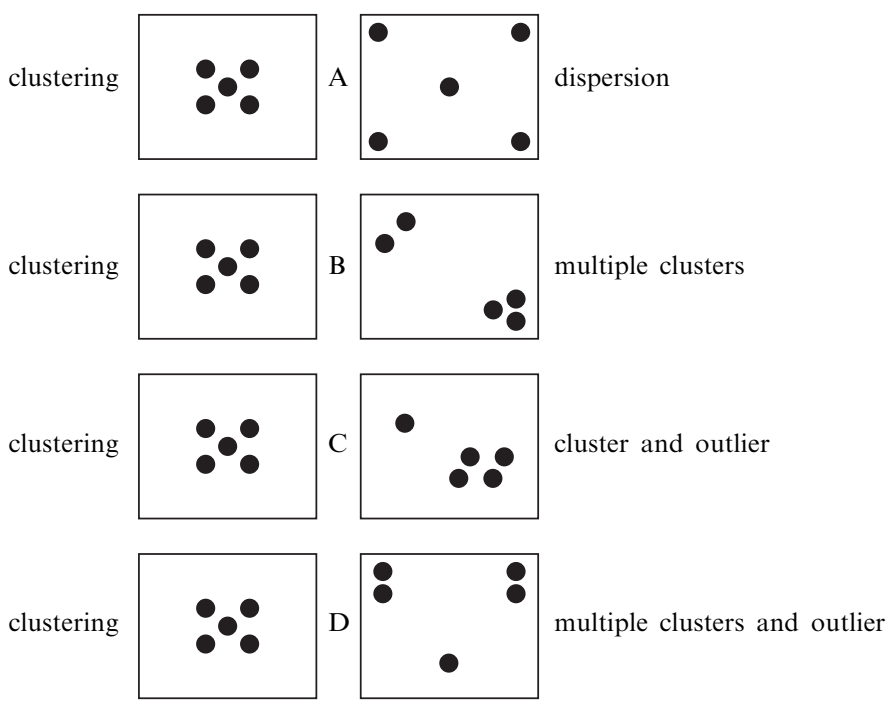

Figure 2. Dimensions of spatial fragmentation.

\subsubsection{Distribution of fragment sizes}

Although the first dimension would imply that all plates broken into equal numbers of fragments are equally fragmented, according to Rutledge (2003) there is another distinguishing factor; it concerns the distribution of the sizes of the fragments (second dimension). Continuing the example above, Rutledge (page 7) suggests that "a plate broken into 10 pieces of equal size is more fragmented than a plate broken into 10 pieces, one of which is $90 \%$ of the original plate." This is also expressed in figures 1 and 2 under the heading of distribution of sizes and can be illustrated with an example about activity participation: if paid labor consists of one big 8-hour activity episode at the office and one smaller episode of 30 minutes at home, the fragmentation is less than if one works 4 hours and 15 minutes both at work and at home.

\subsubsection{Configuration of fragments}

This dimension provides valuable insights into the spatial and temporal patterns formed by the different activity locations and episodes. Because the temporal distances between episodes can be visualized in a single dimension while distances in physical space require two dimensions, we need one subdimension to describe the configuration in time, but two for configuration in space. That is why, in addition to the subdimension that describes the dispersion of the fragments that is relevant for both temporal 
and spatial activity patterns, we have distinguished an extra subdimension for the shape and orientation of the spatial configuration of fragments.

2.2.3.1 Dispersion of fragments When describing the dispersion of fragments across space and time, it is important to draw a distinction between global and local clustering and special cases of clustering where a cluster of a single episode or location occurs, which we would define as an outlier. Global clustering indicates whether the fragments at the level of the total pattern are located relatively nearby or far away (visualized in images $\mathrm{A}$ in figures 1 and 2). Global clustering is thus indicative of the distribution of episodes throughout the day (temporal configuration) and the size of a person's activity space (spatial configuration). However, the extent of clustering at the level of the total activity pattern may mask significant differences within parts of that activity pattern (for example, a certain period of the day or a particular sector of a person's activity space). Therefore, we also consider whether local clusters can be identified. Local clusters are subsets of fragments within the temporal pattern or activity space that are located at a certain temporal or spatial distance from one another (see images B, C, and D in figures 1 and 2). Single fragments that are separated relatively far in time or space from the other fragments (that is, outliers) can be considered special cases of local clustering; they have been visualized in images $\mathrm{C}$ and $\mathrm{D}$ of figures 1 and 2 .

2.2.3.2 Shape and orientation of configuration of fragments Although the title of this paper may suggest otherwise, some locations in physical space are more suitable than others for undertaking a given activity, and existing transportation and communication infrastructures continue to affect what real-time and virtual locations can be visited. Space is not a Euclidean plane or container waiting to be filled by human activity but striated, offering different opportunities for movement and activity participation. It is, structured by, among others, transport and communication infrastructures which bend, shrivel, and shrink space differentially in different directions from any one location. As a result, differences can emerge in the space constituted by the locations where activity episodes have been performed. Thus, a more thorough investigation of the spatial patterns formed by fragmented activity is warranted. When describing spatial patterns, it is common to include an indication of their shape (Ebdon, 1985). The most basic shapes a pattern can take are a line, ellipse, or circle, but polygons are also possible. The pattern of locations of person $\mathrm{A}$ in figure 2, for example, has a roughly circular shape, while person B's image can more readily be described as having an ellipsoid or even linear form. The orientation of the fragments might also be relevant. For instance, the orientation can reveal whether a person's activity patterns are gravitating towards major urban centers, or how activity fragmentation is affected by the configuration of transport and communication infrastructures or a person's commute (home-towork) axis. The significance of the commute axis is evident from the activity-based travel demand literature, which suggests that the combination of home and primary workplace structures how and where people engage in nonwork activities (Damm, 1979; Nishii and Kondo, 1992; Schwanen and Dijst, 2003). In short, the orientation provides important information as to how the fragmentation of activities is affected by the existing urban fabric.

\section{Operationalization of fragmentation measures}

In this section we introduce the measures developed for fragmentation using the dimensions of activity fragmentation discussed in section 2 . The specification and interpretation of each temporal and spatial fragmentation measure are presented below. As mentioned in section 1, the specification of measures for activity 
Table 1. Overview of temporal fragmentation measures.

\begin{tabular}{|c|c|c|c|c|}
\hline \multirow[t]{2}{*}{ Dimension } & \multicolumn{4}{|l|}{ Measures } \\
\hline & symbol & description & values & interpretation \\
\hline $\begin{array}{l}\text { Number of } \\
\text { fragments }\end{array}$ & $E$ & $\begin{array}{l}\text { Number of episodes: the total number of } \\
\text { episodes during a given time period }\end{array}$ & $E \geqslant 1$ & $\begin{array}{l}\text { Larger number indicates more temporal } \\
\text { fragmentation }\end{array}$ \\
\hline $\begin{array}{l}\text { Distribution of } \\
\text { fragment sizes }\end{array}$ & T-index & $\begin{array}{l}\text { Time index: the extent to which the durations } \\
\text { of individual episodes equal one another }\end{array}$ & $0 \leqslant \mathrm{~T}$-index $\leqslant 1$ & $\begin{array}{l}0 \text { indicates that durations are maximally } \\
\text { unequal and that activity fragmentation } \\
\text { is minimal; } 1 \text { indicates that durations } \\
\text { are completely equal to one another } \\
\text { and that activity fragmentation is } \\
\text { maximal }\end{array}$ \\
\hline \multirow[t]{2}{*}{$\begin{array}{l}\text { Configuration } \\
\text { of fragments }\end{array}$} & AID & $\begin{array}{l}\text { Average interepisode duration: the global } \\
\text { clustering/dispersion of episodes along } \\
\text { the time axis }\end{array}$ & $\begin{array}{l}0 \leqslant \text { AID } \leqslant 1442 \\
\text { minutes }\end{array}$ & $\begin{array}{l}\text { Higher values indicate a temporally more } \\
\text { dispersed activity pattern }\end{array}$ \\
\hline & ID-index & $\begin{array}{l}\text { Interepisode duration index: the 'local' } \\
\text { clustering of episodes along time axis }\end{array}$ & $0 \leqslant$ ID-index $\leqslant 1$ & $\begin{array}{l}\text { Higher values indicate that the time } \\
\text { in-between activity episodes is distributed } \\
\text { more evenly }\end{array}$ \\
\hline
\end{tabular}


Table 2. Overview of spatial fragmentation measures.

\begin{tabular}{|c|c|c|c|c|}
\hline \multirow[t]{2}{*}{ Dimension } & \multicolumn{4}{|c|}{ Measures } \\
\hline & symbol & description & values & interpretation \\
\hline $\begin{array}{l}\text { Number of } \\
\text { fragments }\end{array}$ & $L$ & $\begin{array}{l}\text { Number of locations: count of the total } \\
\text { number of activity locations }\end{array}$ & $L \geqslant 1$ & $\begin{array}{l}\text { higher number indicates more spatial } \\
\text { fragmentation }\end{array}$ \\
\hline $\begin{array}{l}\text { Distribution of } \\
\text { fragment sizes }\end{array}$ & S-index & $\begin{array}{l}\text { Spatial index: the way in which the time spent } \\
\text { on a certain activity type on a given day is } \\
\text { fragmented across different locations }\end{array}$ & $0 \leqslant S$-index $\leqslant 1$ & $\begin{array}{l}0 \text { indicates that the activity is not } \\
\text { fragmented spatially, } 1 \text { that the activity } \\
\text { is spatially fragmented completely }\end{array}$ \\
\hline \multirow[t]{5}{*}{$\begin{array}{l}\text { Configuration } \\
\text { of fragments }\end{array}$} & $A$ & $\begin{array}{l}\text { Area index: the global clustering/dispersion } \\
\text { of activity locations }\end{array}$ & $A \geqslant 0$ & $\begin{array}{l}\text { higher values indicate more spatial } \\
\text { fragmentation }\end{array}$ \\
\hline & $R$ & $\begin{array}{l}\text { Cluster index: the degree to which activity } \\
\text { locations are spread evenly across space or } \\
\text { form (local) clusters }\end{array}$ & $0 \leqslant R \leqslant 2.15$ & $\begin{array}{l}\text { a high value indicates that locations are } \\
\text { evenly spread, a low value that there } \\
\text { exist multiple local clusters and } \\
\text { intermediate values that there is one or } \\
\text { more local cluster(s) alongside one } \\
\text { or more outliers }\end{array}$ \\
\hline & $D$ & $\begin{array}{l}\text { Distance: distance between activity locations } \\
(L=2 \text { only })\end{array}$ & $D \geqslant 0$ & $\begin{array}{l}\text { higher values indicate more spatial } \\
\text { fragmentation }\end{array}$ \\
\hline & $\theta$ & $\begin{array}{l}\text { Orientation index: the orientation of } \\
\text { fragmentation, that is, the extent to which the } \\
\text { set of locations is directed towards an arbitrarily } \\
\text { defined axis }\end{array}$ & $0 \leqslant \theta \leqslant 360^{\circ}$ & $\begin{array}{l}\text { interpretation dependent on the nature } \\
\text { of the chosen axis }\end{array}$ \\
\hline & $\tau$ & $\begin{array}{l}\text { Shape index: the degree to which fragmentation } \\
\text { takes the spatial shape of a line or a circle }\end{array}$ & $0 \leqslant \tau \leqslant 1$ & $\begin{array}{l}0 \text { indicates a perfectly linear shape, } \\
1 \text { a perfectly circular shape, and values } \\
\text { between } 0 \text { and } 1 \text { an ellipsoid shape }\end{array}$ \\
\hline
\end{tabular}


fragmentation focuses on paid work. Additionally, in this study we only consider multiple episodes rather than subtasks. Although fragmentation of activities is a process, we limit our analysis to an examination of the temporal and spatial patterns of paid-work episodes. The focus on episodes is justified given that our aim is to investigate spatial and temporal fragmentation rather than functional fragmentation. An episode is defined as the time span used for a more or less uniform and coherent set of actions (eg reading e-mail, attending a meeting), suggesting that spatial and temporal fixity or flexibility can be well defined at the episode level. Therefore, it is a logical measurement unit when investigating spatial and temporal fragmentation. For this study we apply the measures to the time scale of the day, because this time frame is commonly used in the analysis of activity-travel patterns. However, it should be appreciated that the proposed measures can be used to evaluate activity fragmentation on multiple time scales (eg days, weeks). An overview of the measures is given in tables 1 and 2.

\subsection{Measures for the number of the fragments}

The first dimension is operationalized through two measures: the number of episodes and the number of locations. The number of episodes can be quantified by counting the different episodes of a certain activity. As before, an episode is defined as an uninterrupted stretch of time devoted to a paid-work subtask. Similarly, the number of locations is measured by counting the number of locations where a particular type of activity - here paid work - is conducted on a given day.

$$
E=\sum_{i=1}^{n} e_{i} \text {, and } L=\sum_{j=1}^{n} l_{j},
$$

where $E$ is the total number of activity episodes on a given day and $e_{i}$ is the $i$ th paidwork episode; $L$ is the total number of work locations and $l_{j}$ is the $j$ th work location. The interpretation of these measures is straightforward: greater numbers indicate more fragmentation. If we look at figure 1, we see that the right-hand image is more fragmented $(E=7)$ than the left-hand image $(E=3)$.

\subsection{Measures for the distribution of fragment sizes}

The distribution of the fragment sizes is measured by the time index and the spatial index. The time index is based on the number of minutes allocated to a certain episode; the spatial index describes how the time spent on the episodes is distributed across different locations. The distribution of time can be represented as:

$$
\begin{aligned}
& \text { across different episodes: } T=\left(t_{e 1}, t_{e 2}, \ldots, t_{e E}\right), \\
& \text { across different locations: } T=\left(t_{l 1}, t_{l 2}, \ldots, t_{l L}\right),
\end{aligned}
$$

where $T$ is the total time spent on work activities on a given day; $t_{e 1}, t_{e 2}, \ldots, t_{e E}$ is the time spent during the 1st, 2 nd, ..., and $E$ th episodes, respectively; $t_{l 1}, t_{l 2}, \ldots, t_{l L}$ is the time spent at the 1 st, $2 \mathrm{nd}, \ldots$, and $L$ th locations, respectively.

The time index is obtained in three steps. First, we divided the duration of each episode by the total time spent on paid work on a given day, take the square of each fraction and sum these across episodes. Second, we subtract that sum from 1 so that greater values are indicative of more fragmentation. Finally, we control for the differences in the number of episodes by dividing the intermediate outcome by $1-(1 / E)$ if $E>1$. More formally, the time index (T-index) can be defined as:

$$
\left.\begin{array}{r}
{\left[1-\sum_{i=1}^{E}\left(\frac{t_{e i}}{T}\right)^{2}\right] /\left(1-\frac{1}{E}\right), \quad \text { if } E>1,} \\
0, \quad \text { if } E=1 .
\end{array}\right\}
$$


The spatial index ( $S$-index) is defined in an analogous manner:

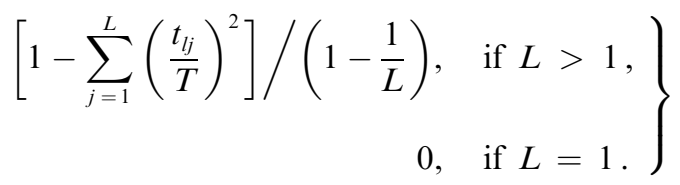

\subsection{Measures for the configuration of the fragments}

Two measures have been developed to represent the configuration of the fragments dimension of the temporal fragmentation; five measures are used to describe the configuration of the fragments of spatial fragmentation. We start with the specification of measures for temporal fragmentation and then proceed with the description of measures for the configuration of the spatial fragmentation.

\subsubsection{Temporal fragmentation}

The first measure for the configuration of the fragments in the temporal domain is the average interepisode duration (AID). The AID indicates the global clustering or dispersion of episodes for the day as a whole. Suppose a certain number of work episodes is given. Let $S_{e 1}, S_{e 2}, S_{e 3} \ldots S_{E-1}, S_{E}$ and $F_{e 1}, F_{e 2}, F_{e 3} \ldots F_{E-1}, F_{E}$ be the start and end times of each episode, respectively. The interepisode duration can then be defined as:

$$
d_{i}=S_{e i}-F_{e i-1}
$$

where $d_{i}$ is the duration between $i$ th and $(i-1)$ th episodes, $S_{e i}$ is the starting time of the $i$ th episode, and $F_{e i-1}$ is the ending time of the $(i-1)$ th episode. The mean distance between episodes (AID) is then:

$$
\frac{\sum_{i=1}^{E-1} d_{i}}{E-1} .
$$

The second measure for the configuration of the fragments is the interepisode duration index (ID-index). This indicates the local clustering of episodes along the time axis and indicates whether the time spans between episodes have a similar duration, as shown in figure 1 . The specification of this measure resembles the T-index but is based on the between-episode time duration (time spent on nonwork activities). The ID-index is defined as:

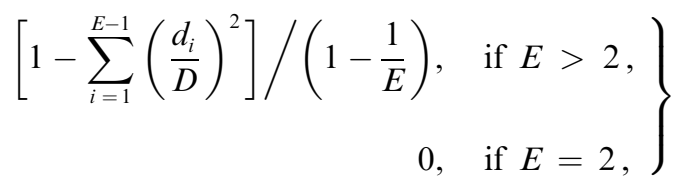

where $D$ is the sum of intervals between episodes and $D>1$. Values close to 0 indicate that all activity episodes follow each other immediately, except one that takes place at another time of day. Values closer to 1 imply that the intervals between episodes are of equal duration, and that no local clustering of episodes (in time) takes place. As a set the AID and ID-index measures provide an indication of how a person's paid work is spread more or less evenly across the day.

\subsubsection{Spatial fragmentation}

As noted above, the spatial configuration of the fragments is reflected by five measures: the area index, cluster index, distance, orientation index, and shape index. We have chosen these measures because they provide a clear indication of the pattern, direction, 
shape, and extent of the fragmentation of an activity. The first three measures represent the dispersion of the fragments, while the last two measures describe the shape and orientation of configuration of the fragments.

The area index describes the global clustering or dispersion of activity. It is associated with the standard deviational ellipse (SDE) which was first developed by Furfey (1927) and Lefever (1926) and has been widely used in spatial analysis to describe the spatial configuration of a set of locations. The SDE is less sensitive to outliers than the standard distance (SD) (Buliung and Kanaroglou, 2006). The SD is defined as the standard deviation of the distance between any location and the mean center of a point pattern (see Bachi, 1962, for details). The concept of the SDE is described as follows: the SDE is centered on the mean center of the activity locations; the long axis of the ellipse represents the maximum dispersion of the locations, while the short axis is perpendicular to the long axis at the mean center and shows the minimum dispersion of the activity locations. The respective standard deviations along these two axes define the SDE. Note that the long $\left(x^{\prime}\right)$ and short $\left(y^{\prime}\right)$ axis of the SDE are rotated relative to the $x$ and $y$ axis of the coordinate system with an angle $\theta$. The standard deviations of the fragments (locations) along the $x^{\prime}$ and $y^{\prime}$ axes are calculated as:

$$
\sigma_{x^{\prime}}=\left[\frac{\sum_{j=1}^{L}\left(\tilde{x}_{j} \cos \theta+\tilde{y}_{j} \sin \theta\right)^{2}}{L}\right]^{1 / 2}, \quad \sigma_{y^{\prime}}=\left[\frac{\sum_{j=1}^{L}\left(\tilde{x}_{j} \sin \theta-\tilde{y}_{j} \cos \theta\right)^{2}}{L}\right]^{1 / 2},
$$

where $\sigma_{y^{\prime}}$ is the standard deviation of the locations along the $y^{\prime}$ axis, $\sigma_{x^{\prime}}$ is the standard deviation of the locations along the $x^{\prime}$ axis, $\tilde{x}$ and $\tilde{y}$ are the deviations of the $x, y$ coordinates from the mean center $\mathrm{MC}=\{\bar{X}, \bar{Y}\}$ and $\cos \theta$ and $\sin \theta$ are the cosine and sine of angle $\theta$, which is defined below in equation (14). The area index $(A)$ is calculated as:

$$
A=\pi a b \text {, }
$$

where $A$ is the area index, $a$ is the semimajor axis of the $\operatorname{SDE}\left(a=\sigma_{x^{\prime}}\right)$, and $b$ is the semiminor axis of the $\operatorname{SDE}\left(b=\sigma_{y^{\prime}}\right)$. The interpretation of this measure is straightforward: a greater value indicates more fragmentation.

The cluster index indicates whether the activity locations form clusters or are spread more evenly across space and is thus a measure of the degree of both global and local clustering. It is related to the nearest neighbor distance (NND), $\Delta$, which is defined as

$$
\Delta=\frac{\sum_{j=1}^{L} \delta_{j}}{L},
$$

where $\delta_{j}$ is the nearest neighbor distance for each activity location $j$, and $L$ is the total number of activity locations. As the NND is sensitive to both the number of locations $L$ and the area covered by the locations, we standardize it by comparing it with the completely random point pattern $\delta_{s}$. $\delta_{s}$ is defined as:

$$
\delta_{s}=\left[2\left(\frac{L}{A}\right)^{1 / 2}\right]^{-1},
$$

where $A$ is the area of the circle with the SD as radius (Bachi, 1962). Then the cluster index is obtained by calculating the ratio between $\Delta$ and $\delta_{s}$ :

$$
R=\frac{\Delta}{\delta_{s}}
$$


where $R$ is the cluster index of fragments $(0<R<2.15)$. High values for the cluster index suggest that locations are evenly spread, and low values that there are multiple local clusters; intermediate values are indicative of one or several clusters in combination with outliers.

The area and cluster indices are only meaningful for $L>2$; if there are only two activity locations, the area index and NND resolve to the straight-line distance between the locations. We use the distance $(D)$ between the two locations as an indicator of spatial dispersion for the special case of $L=2$.

The final two indicators describe the shape and orientation of the spatial configuration; both can be derived from the SDE. The orientation index $(\theta)$ describes the orientation of the activity locations and is equivalent to the angle between the long axis of the SDE and the $x$-axis, as noted before. It can be obtained by using $\tilde{x}_{j}$ and $\tilde{y}_{j}$ :

$$
\tan \theta=\left\{\sum_{j} \tilde{x}_{j}^{2}-\sum \tilde{y}_{j}^{2}+\left[\left(\sum_{j} \tilde{x}_{j}^{2}-\sum \tilde{y}_{j}^{2}\right)^{2}+4 \sum_{j} \tilde{x}_{j} \tilde{y}_{j}\right]^{1 / 2}\right\} / 2 \sum_{j} \tilde{x}_{j} \tilde{y}_{j} .
$$

Values of the measure describe the orientation of activity locations. The value of 0 , for instance, indicates that activity locations are oriented along the east - west direction. Angles can be standardized along any arbitrary axis. The shape index $(\tau)$ describes the shape in which activity locations are fragmented: for example, a circular or linear shape. The shape index is described as the ratio of the minor and major axes of the SDE:

$$
\tau=\frac{a}{b}
$$

where $a$ is the minor axis of the SDE $a=\sigma_{y^{\prime}}$ and $b$ is the major axis of the SDE $b=\sigma_{x^{\prime}}$. The value of the shape index ranges from 0 to 1 : a value 1 indicates a perfectly circular shape, the minimum value 0 indicates a linear shape, and values between 0 and 1 an ellipsoid shape. Note that this measure is similar to the anisotropy ratio applied by González et al (2008). However, whereas the shape index is applied to locations visited for work purposes by a single individual in our study, González et al apply the measure to describe the aggregated locations of individuals in a population irrespective of activity. While the shape index can only be used for $L>2$, it is possible to employ the orientation index for $L=2$.

\section{Research design}

\subsection{Data}

The data we have used consist of two-day activity - travel diaries collected from single earner and dual-earner households residing in the Utrecht-Amersfoort-Hilversum region in the Netherlands in 2007. The data were collected in the following stages. First, selection questionnaires were sent to about 13500 respondents living in various neighborhoods in the research area. Addresses within each neighborhood were selected randomly using digital files containing all street addresses. Households were sent a selection questionnaire about general household characteristics (eg, gender, age, employment status), possession of ICT devices, and in addition whether they would like to participate in the main survey. This main survey provided more detailed information about sociodemographics and ICT availability and usage and included a two-day activity - travel diary. In total, the main questionnaire was completed by approximately 740 respondents, either online or in a mail-out/mail-back paper-and-pencil format; the activity and travel diary was completed by 662 respondents (paper-and-pencil format only).

We selected this dataset because it allowed us to test the set of fragmentation measures developed. In the diary, the respondents were asked to report the activities in which they were engaged, at what location, for how long, and with whom. For paid work, 
respondents were asked to report various subtasks (see subsection 4.2), enabling the calculation of fragmentation measures for the work activity. With regard to travel, the respondents were asked to report what transport mode they had used, with whom they traveled, for how long, and what other activities (eg reading, working, listening to music, sleeping) they engaged in while traveling. They were also asked to provide details about their electronic communication (duration, purpose, type of communication mode, and with whom they communicated) at stationary locations and when traveling. Further information about the data is available in Tillema et al (2010).

The raw data were further screened to examine the fragmentation of paid work. As the measures developed in section 3 are sensitive to the total work duration, we selected for empirical analysis only full-time workers who worked between 7 and 10 hours on the given diary day. In the descriptive analyses of measures for the number of fragments and the distribution of fragment sizes dimension, we used 407 person days of 321 individuals.

Table 3. Frequency distribution for explanatory factors.

\begin{tabular}{|c|c|c|}
\hline & Categories & Frequency \\
\hline \multicolumn{3}{|l|}{ ICT ownership and use } \\
\hline \multirow[t]{3}{*}{ Possession of PDA ${ }^{\mathrm{a}}$} & yes & $10.8 \%$ \\
\hline & no & $89.2 \%$ \\
\hline & number of observations & 407 \\
\hline \multirow[t]{3}{*}{ Possession of laptop } & yes & $24.6 \%$ \\
\hline & no & $75.4 \%$ \\
\hline & number of observations & 407 \\
\hline \multirow{4}{*}{ General Internet use } & $<2$ hours per week & $30.5 \%$ \\
\hline & $2-5$ hours per week & $33.8 \%$ \\
\hline & $>5$ hours per week & $35.7 \%$ \\
\hline & number of observations & 311 \\
\hline \multicolumn{3}{|l|}{ Employment situation } \\
\hline \multirow[t]{7}{*}{ Occupation type } & manager & $6.3 \%$ \\
\hline & high professional & $47.7 \%$ \\
\hline & low professional & $29.4 \%$ \\
\hline & clerical staff & $10.1 \%$ \\
\hline & service worker & $4.3 \%$ \\
\hline & skilled worker & $2.3 \%$ \\
\hline & number of observations & 398 \\
\hline \multirow{4}{*}{$\begin{array}{l}\text { Employment time } \\
\text { autonomy }\end{array}$} & complete autonomy & $23.7 \%$ \\
\hline & partial autonomy & $56.8 \%$ \\
\hline & no autonomy & $19.6 \%$ \\
\hline & number of observations & 317 \\
\hline \multirow{4}{*}{ Working from home } & never & $60.7 \%$ \\
\hline & sometimes & $27.9 \%$ \\
\hline & at least once a week & $11.4 \%$ \\
\hline & number of observations & 359 \\
\hline \multicolumn{3}{|c|}{ Sociodemographic factors } \\
\hline \multirow[t]{3}{*}{ Gender } & male & $53.7 \%$ \\
\hline & female & $46.3 \%$ \\
\hline & number of observations & 404 \\
\hline \multirow[t]{6}{*}{ Urbanization degree } & $<500$ addresses $/ \mathrm{km}^{2}$ & $25.3 \%$ \\
\hline & $500-1000$ addresses $/ \mathrm{km}^{2}$ & $19.1 \%$ \\
\hline & $1001-1500$ addresses $/ \mathrm{km}^{2}$ & $22.0 \%$ \\
\hline & $1501-2500$ addresses $/ \mathrm{km}^{2}$ & $14.0 \%$ \\
\hline & $>2500$ addresses $/ \mathrm{km}^{2}$ & $19.6 \%$ \\
\hline & number of observations & 372 \\
\hline
\end{tabular}


This sample is not representative of the Dutch population. Table 3 shows that our sample is characterized by an overrepresentation of high-level professionals (47.4\%) and highly educated people. We deliberately oversampled these people, because we expected them to be more likely to fragment their paid-work activity.

The distribution of autonomy over employment times indicates that about one fifth of the respondents experience no autonomy, which may be interpreted as circumstantial evidence that most people fragment paid work at least to some extent because they choose to do so. About $11 \%$ of the respondents work at home for at least one day a week. The proportions of men and women in the sample are 54\% and $46 \%$ respectively. Only $11 \%$ of the total sample reported that they had a PDA (personal digital assistant) and $25 \%$ had a laptop computer. Excluding time spent on e-mailing, in chat-rooms, or on instant messaging services, almost $36 \%$ of the respondents use the Internet for at least 5 hours per week.

\subsection{Defining paid-work activities}

In the current study, a paid-work activity is defined as comprising one of the following subtasks: work-related meeting, work-related e-mailing, work-related Internet browsing, working while traveling, and other work (eg, reading articles, writing reports). It should be noted that work-related e-mailing only includes the reading of e-mails and not their composition. Besides the general activity and travel sections, the diary had a separate section for recording electronic communications. The writing of e-mails was part of the separate electronic communications section, because we wanted to know to whom work-related e-mails were sent (in the context of another research project). To lower respondent burden, we decided not to ask participants to provide information about the persons from whom they received e-mails. Because of this choice, we could include the reading of work-related e-mails in the general activity section rather than the section on electronic communications. Pretests with the diary suggested that this distinction worked well for study participants. We also reduced respondent burden by asking respondents only about the duration of electronic communication episodes and not about start and ending times. Not knowing the exact start and ending times of the communication episodes made it impossible to determine whether the writing of workrelated e-mails took place during work or nonwork activities. Consequently, if the writing of work-related e-mails took place during another paid-labor subtask, this would result in an overestimation of the actual time devoted to paid labor. This is why we opted not to take them into consideration in our analyses. The start and end times of paid work undertaken while traveling were derived in the following way. The respondents reported whether they engaged in work activities while traveling. For the travel episodes, they only provided the departure and end times of the trip. Thus, on the basis of this information, we inferred the start and end times of work activities on the road. Most respondents who worked while traveling used a multitrip mode with the train as their main mode. Krygsman et al (2004) found that about $20 \%-50 \%$ of the duration of multimodal trips in the Netherlands was spent on access and egress travel. From this finding, we assumed that people spent only $50 \%$ of the time during the multimode trip on paid work.

As indicated in our data, paid work was performed at two generic types of location: stationary and mobile locations. The identification of a stationary location was straightforward, based on street addresses. Mobile locations were identified as follows: all trips on a given day between the same two street addresses (origin and destination) were considered to constitute one unique location. If a person worked on commute trips while traveling both from and to home, both work episodes were considered to be performed at the same location. Work activities performed on trips 
with different origins or destinations were considered to be conducted at different locations.

\subsection{Explanatory factors}

On the basis of past studies, we expected fragmentation to vary systematically with a person's ICT ownership and use, employment situation, and sociodemographic background (Hjorthol, 2002; Hubers et al, 2008; Kakihara and Sørensen, 2004; Lenz and Nobis, 2007). More specifically, those using portable devices such as PDAs and laptops and using the Internet more extensively on a weekly basis were hypothesized to have more temporally and spatially fragmented work patterns. We also expected that people who have more time autonomy over employment times and who work at home more often would have more work episodes and/or would engage in paid labor at more locations. Occupation type might also be relevant, with managers and (higher) professionals having more fragmented work patterns than clerical staff, service workers, and skilled workers. Women could also be expected to have more fragmented work patterns than men. This is because they face more space-time constraints due to the unequal division of housework and childcare between spouses and women are more likely than men to schedule paid-labor activities around domestic commitments (Kwan, 2000; Schwanen, 2007). Furthermore, as urban areas offer a greater variety of facilities, we expect people living in urbanized areas to exhibit temporally and spatially more fragmented paid-work patterns than people residing in less urbanized areas.

These expectations were tested using bivariate statistical analysis. The purpose of that analysis was to explore the characteristics and behavior of the proposed indicators rather than to establish which factors are ceteris paribus most strongly related with variations in activity fragmentation. That is why we use bivariate rather than multivariate statistical tests.

\section{Empirical results}

\subsection{Paid work in space and time}

The distribution of paid-work episodes across different locations is presented in figure 3. It shows that paid-work activities are not performed only at work locations. The vast majority $(85 \%)$ of paid-work activities are conducted at employment locations, but $7 \%$ are undertaken elsewhere and $6 \%$ are performed at home. The lowest share of paid-work activities $(2 \%)$ was performed on the road. In terms of which subtasks respondents undertake at various locations, figure 4 shows that e-mail and Internet browsing are undertaken relatively often at home and the primary workplace. Most meetings take place elsewhere. Yet, the subtask other dominates at all location types.

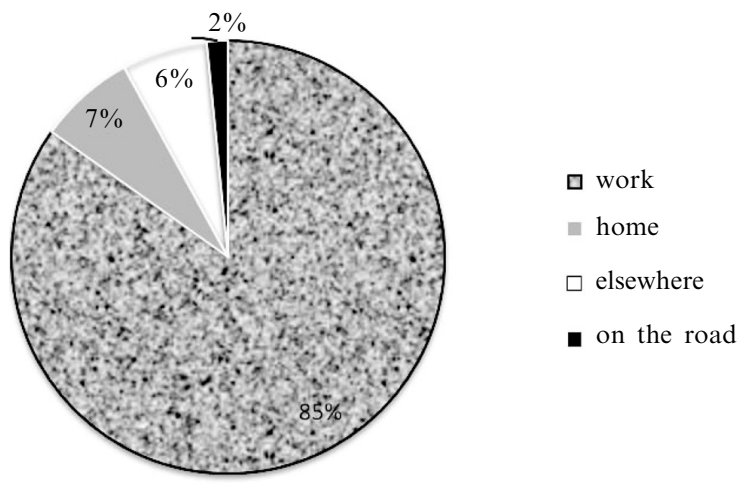

Figure 3. Percentage of paid-work episodes, by location. 


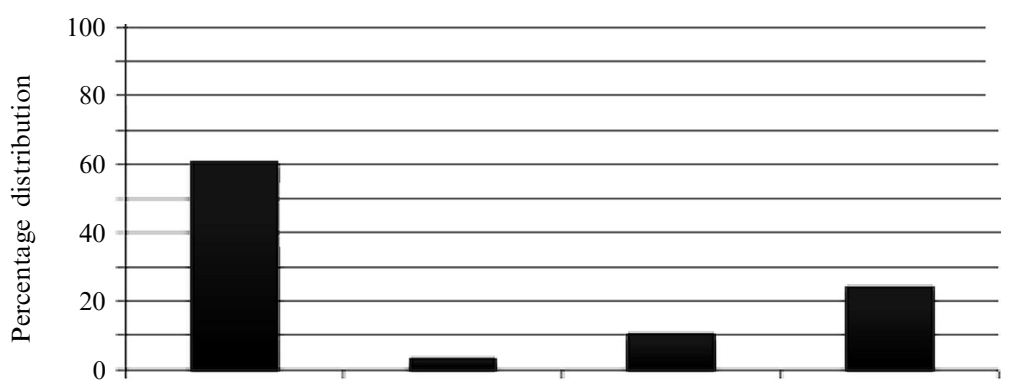

(a)

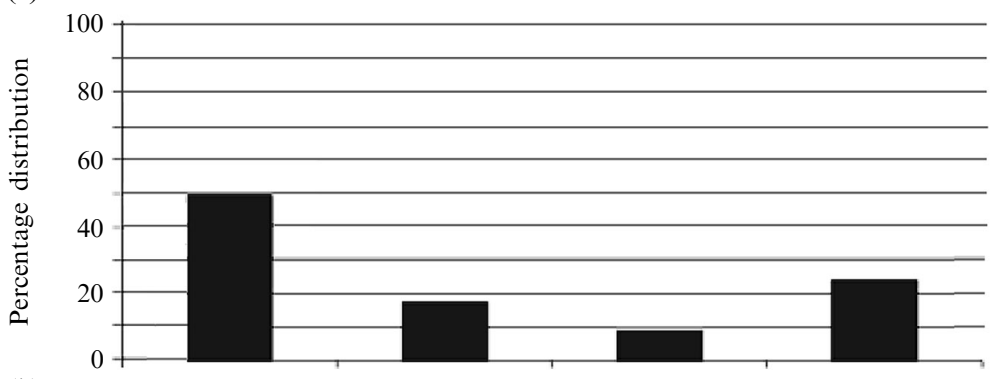

(b)

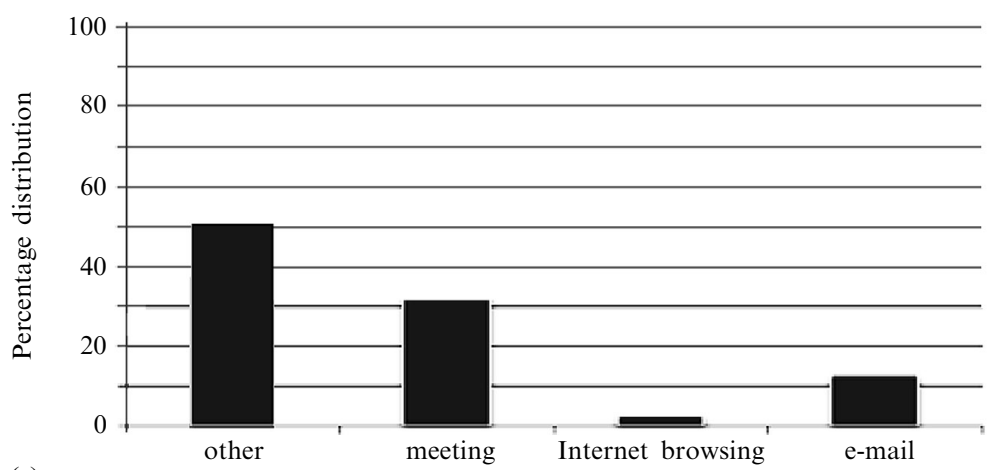

(c)

Paid-work episodes

Figure 4. Percentage of paid-work episodes, by location and subtask. (a) At home; (b) at work; (c) elsewhere.

With regard to the duration of activity episodes, we see that those belonging to the category other last the longest, 145.0 minutes on average. As expected, e-mail episodes consume the least time (39.1 minutes on average). The average durations for meeting episodes and Internet browsing episodes are 66.2 and 61.4 minutes, respectively.

\subsection{Number of fragments}

With regard to the first fragmentation dimension, table 4 shows that the individuals in our sample have on average 7.47 paid-work episodes and work at 1.42 locations on a given day, indicating that most people engage in paid labor at the primary work location. There are, however, considerable differences in the number of fragments according to ICT ownership and use, employment situation, and sociodemographic background. With regard to temporal fragmentation, the analysis indicates that individuals with a PDA, who make extensive general use of the Internet, work in managerial, highlevel professional occupations (eg scientific, technical, health care, ICT), have complete or partial autonomy over their employment times or regularly work from home have, on average, more paid-work episodes than others. These findings are consistent with our 
Table 4. Descriptive statistics for the number of fragments.

Number of observations
Number of Number of episodes: locations $E$ (mean) $\quad L$ (mean)
ICT ownership and use

Possession of laptop

General Internet use

Employment time autonomy

Working from home

\section{Employment situation}

Occupation type

Employment time
autonomy

Sociodemographic factors
Gender

Socioder
Gender

Urbanization degree
Possession of PDA $^{\mathrm{a}}$

yes
no
Mann-Whitney test
yes
no
Mann-Whitney test
$<2$ hours per week
$2-5$ hours per week
$>5$ hours per week
Kruskal-Wallis test

\section{manager}

high professional

low professional

clerical staff

service worker

skilled worker

Kruskal-Wallis test complete autonomy partial autonomy no autonomy

Kruskal-Wallis test never sometimes at least once a week Kruskal-Wallis test

25
190
117
40
17
9

75
180
62

218
100
41


217
187

94
71
82
52
73

Total

a $\mathrm{PDA}=$ personal digital assistant.

$\begin{array}{ll}9.47 & 1.52 \\ 7.23 & 1.41 \\ p=0.000 & p=0.200 \\ 7.78 & 1.52 \\ 7.37 & 1.39 \\ p=0.227 & p=0.187 \\ 6.83 & 1.42 \\ 7.44 & 1.44 \\ 8.27 & 1.47 \\ p=0.098 & p=0.581\end{array}$

$\begin{array}{ll}9.68 & 1.96 \\ 8.16 & 1.54 \\ 6.97 & 1.25 \\ 6.77 & 1.12 \\ 4.00 & 1.18 \\ 4.22 & 1.55 \\ p=0.000 & p=0.000 \\ 7.98 & 1.75 \\ 7.77 & 1.38 \\ 5.53 & 1.19 \\ p=0.001 & p=0.000 \\ 6.72 & 1.28 \\ 8.38 & 1.67 \\ 8.73 & 1.68 \\ p=0.000 & p=0.000\end{array}$

$7.54 \quad 1.48$

$7.40 \quad 1.35$

$p=0.938 \quad p=0.094$

$\begin{array}{ll}7.60 & 1.40\end{array}$

$\begin{array}{ll}7.87 & 1.37\end{array}$

$7.49 \quad 1.61$

$6.84 \quad 1.25$

$7.09 \quad 1.40$

$p=0.449 \quad p=0.070$

$7.47 \quad 1.42$

expectations reported in subsection 4.3. Contrary to expectations, we see that the difference between men and women is not statistically significant. Presumably this is because many part-time workers, a majority of whom are female in the Netherlands (van Wel and Knijn, 2007), have been excluded from our analysis. We expected activity fragmentation to be a means for women to fulfill domestic and employment responsibilities, which would result in more temporal fragmentation. This, however, does not seem to hold for women working fulltime.

As far as the number of locations is concerned, the results indicate that managers, workers who have complete autonomy over their employment times, workers who sometimes work from home, and men work at more different locations than 
individuals who work in other occupations, workers who do not have time autonomy, workers who never work from home, and women. That men's paid work is spatially more fragmented than women's is not consistent with expectations and the results for temporal fragmentation. This might reflect differences in type of occupation and job specification; future research using multivariate statistical methods might shed light on this issue. There are also statistically significant differences in spatial fragmentation according to the degree of urbanization, but this relationship is clearly nonsystematic. This suggests that the effect is caused by one or more third-party factors whose values vary spatially. Exploring the nature of those third-party factors is, however, beyond the scope of this study. With respect to the ICT factors, only PDA possession and overall weekly Internet use are positively correlated with the level of temporal fragmentation of paid work, but the effects are very weak and not statistically significant $(p<0.10)$.

In general, the outcomes for the first dimension of fragmentation concur with most of our a priori expectations. Nonetheless, employment factors are more clearly related to the number of fragments than to ICT and sociodemographic factors.

\subsection{Distribution of fragment sizes}

With respect to the second dimension of fragmentation, table 5 indicates that the average values of the T-index and S-index are 0.37 and 0.11 , respectively, suggesting that the time spent on paid work is more evenly distributed across different episodes than across locations. This inference reflects the dominance of the traditional workplace (figure 3), even when time is more evenly spread across various subtasks. Furthermore, from table 5 we see that the durations of paid-work episodes are more equal to one another for individuals with a laptop; other differences are too small to be statistically significant $(p<0.10)$. Concerning spatial fragmentation, we see that the time spent on paid work is more evenly distributed across different locations for managers, high-level professionals, workers who sometimes or at least once per week work from home, and for men than for those in lower level occupations, who never work from home, and women. The average is also rather high for skilled workers, but this seems to reflect the small number of respondents $(n=9)$ in this category rather than a robust result. Finally, the distribution of sizes is also more equal as respondents have more autonomy over their employment times.

Overall, there are not only fewer differences in the T-index than in the S-index but also, more generally, in the distribution of fragment sizes dimension than in the number of fragments dimension. These variations seem to reflect the nature of the activity type considered rather than the measures used. At least for the respondents in our study, paid work is for the most part undertaken at the (first) workplace in relatively large, continuous blocks of time (see subsection 5.1).

\subsection{Temporal configuration of fragments}

Table 6 shows that there are often sizable gaps between paid-work episodes: the AID is 23.2 minutes and the mean score for the ID-index is 0.29 . The difference in the mean AID is not statistically significant $(p<0.10)$ for the ICT-related factors. Regarding the ID-index, we see that the paid-work episodes of people without a PDA are more equally distributed across the time between the first and last episode than are those of people who do own a PDA. The paid-work patterns of the latter are more likely to take the form of several successive episodes and a single outlier, possibly reflecting the fact that the PDA allows them to perform some paid labor in the evening outside traditional office hours. This finding was expected, since we expected that a PDA would result in more temporal fragmentation.

With regard to the employment-related factors, the AID shows us that the paidlabor activities of workers who can choose their own start and end times or who 
Table 5. Descriptive statistics for the distribution of fragment sizes.

\begin{tabular}{|c|c|c|c|c|}
\hline & & $\begin{array}{l}\text { Number of } \\
\text { observations }\end{array}$ & $\begin{array}{l}\text { T-index } \\
\text { (mean) }\end{array}$ & $\begin{array}{l}\text { S-index } \\
\text { (mean) }\end{array}$ \\
\hline \multicolumn{5}{|l|}{ ICT ownership and use } \\
\hline \multirow[t]{3}{*}{ Possession of PDA ${ }^{\mathrm{a}}$} & yes & 44 & 0.29 & 0.11 \\
\hline & no & 363 & 0.37 & 0.10 \\
\hline & Mann-Whitney test & & $p=0.274$ & $p=0.303$ \\
\hline \multirow[t]{3}{*}{ Possession of laptop } & yes & 100 & 0.32 & 0.13 \\
\hline & no & 307 & 0.39 & 0.10 \\
\hline & Mann-Whitney test & & $p=0.052$ & $p=0.217$ \\
\hline \multirow{4}{*}{ General Internet use } & $<2$ hours per week & 95 & 0.40 & 0.34 \\
\hline & $2-5$ hours per week & 105 & 0.39 & 0.29 \\
\hline & $>5$ hours per week & 111 & 0.34 & 0.44 \\
\hline & Kruskal-Wallis test & & $p=0.626$ & $p=0.536$ \\
\hline \multicolumn{5}{|l|}{ Employment situation } \\
\hline \multirow{7}{*}{ Occupation type } & manager & 25 & 0.32 & 0.25 \\
\hline & high professional & 190 & 0.34 & 0.13 \\
\hline & low professional & 117 & 0.37 & 0.06 \\
\hline & clerical staff & 40 & 0.40 & 0.04 \\
\hline & service worker & 17 & 0.41 & 0.06 \\
\hline & skilled worker & 9 & 0.48 & 0.23 \\
\hline & Kruskal-Wallis test & & $p=0.491$ & $p=0.000$ \\
\hline \multirow{4}{*}{$\begin{array}{l}\text { Employment time } \\
\text { autonomy }\end{array}$} & complete autonomy & 74 & 0.40 & 0.18 \\
\hline & partial autonomy & 180 & 0.34 & 0.10 \\
\hline & no autonomy & 62 & 0.43 & 0.05 \\
\hline & Kruskal-Wallis test & & $p=0.405$ & $p=0.000$ \\
\hline \multirow[t]{4}{*}{ Working from home } & never & 218 & 0.37 & 0.07 \\
\hline & sometimes & 100 & 0.36 & 0.16 \\
\hline & at least once a week & 41 & 0.33 & 0.18 \\
\hline & Kruskal-Wallis test & & $p=0.768$ & $p=0.000$ \\
\hline \multicolumn{5}{|c|}{ Sociodemographic factors } \\
\hline \multirow[t]{3}{*}{ Gender } & male & 217 & 0.38 & 0.12 \\
\hline & female & 187 & 0.33 & 0.08 \\
\hline & Mann-Whitney test & & $p=0.304$ & $p=0.071$ \\
\hline \multirow{6}{*}{ Urbanization degree } & $<500$ addresses $/ \mathrm{km}^{2}$ & 94 & 0.38 & 0.10 \\
\hline & $500-1000$ addresses $/ \mathrm{km}^{2}$ & 71 & 0.34 & 0.08 \\
\hline & $1001-1500$ addresses $/ \mathrm{km}^{2}$ & 82 & 0.34 & 0.15 \\
\hline & $1501-2500$ addresses $/ \mathrm{km}^{2}$ & 52 & 0.34 & 0.08 \\
\hline & $>2500$ addresses $/ \mathrm{km}^{2}$ & 73 & 0.40 & 0.11 \\
\hline & Kruskal-Wallis test & & $p=0.816$ & $p=0.113$ \\
\hline \multicolumn{3}{|l|}{ Total } & 0.37 & 0.11 \\
\hline${ }^{\text {a }} \mathrm{PDA}=$ personal $\mathrm{d}$ & assistant. & & & \\
\hline
\end{tabular}

regularly work from home tend to be more dispersed across the day than those of their counterparts. As indicated by the ID-index, the intervals between episodes are also more evenly distributed. Thus, the paid work of individuals with more autonomy over employment time and who regularly work from home is more temporally fragmented, which concurs with expectations. Somewhat contrary to expectations, we see that for men the intervals between paid-work episodes are also more equal to one another, suggesting that their paid work is more temporally fragmented than that of women. There is also a statistically significant difference in the interepisodes duration index by urbanization degree although again this relationship is not systematic and presumably is caused by third-party variables whose values vary spatially. 
Table 6. Descriptive statistics for the temporal configuration of fragments.

\begin{tabular}{|c|c|c|c|c|c|}
\hline & & \multicolumn{2}{|l|}{ AID } & \multicolumn{2}{|l|}{ ID-index } \\
\hline & & $\begin{array}{l}\text { number of } \\
\text { observations }\end{array}$ & mean & $\begin{array}{l}\text { number of } \\
\text { observations }\end{array}$ & mean \\
\hline \multicolumn{6}{|c|}{ ICT ownership and use } \\
\hline Possession & yes & 44 & 20.9 & 43 & \multirow{7}{*}{$\begin{array}{l}0.20 \\
0.30 \\
p=0.065 \\
0.33 \\
0.28 \\
p=0.205 \\
0.31 \\
0.28 \\
0.28 \\
p=0.785\end{array}$} \\
\hline of $\mathrm{PDA}^{\mathrm{a}}$ & $\begin{array}{l}\text { no } \\
\text { Mann-Whitney test }\end{array}$ & 330 & $\begin{array}{l}23.5 \\
p=0.221\end{array}$ & 277 & \\
\hline Possession & yes & 91 & 24.4 & 82 & \\
\hline of laptop & $\begin{array}{l}\text { no } \\
\text { Mann-Whitney test }\end{array}$ & 283 & $\begin{array}{l}22.8 \\
p=0.804\end{array}$ & 238 & \\
\hline General & $<2$ hours per week & 86 & 25.1 & 70 & \\
\hline Internet & $2-5$ hours per week & 99 & 25.6 & 84 & \\
\hline use & $\begin{array}{l}>5 \text { hours per week } \\
\text { Kruskal-Wallis test }\end{array}$ & 104 & $\begin{array}{l}23.7 \\
p=0.102\end{array}$ & 97 & \\
\hline \multicolumn{6}{|c|}{ Employment situation } \\
\hline Occupation & manager & 25 & 37.8 & 22 & 0.37 \\
\hline \multirow[t]{6}{*}{ type } & high professional & 180 & 23.3 & 157 & 0.31 \\
\hline & low professional & 106 & 19.4 & 85 & 0.28 \\
\hline & clerical staff & 36 & 20.3 & 33 & 0.18 \\
\hline & service worker & 11 & 19.4 & 10 & 0.26 \\
\hline & skilled worker & 7 & 39.1 & 5 & 0.54 \\
\hline & Kruskal-Wallis test & & $p=0.328$ & & $p=0.122$ \\
\hline \multirow{3}{*}{$\begin{array}{l}\text { Employment } \\
\text { time } \\
\text { autonomy }\end{array}$} & complete autonomy & 71 & 30.8 & 63 & 0.38 \\
\hline & partial autonomy & 167 & 24.5 & 147 & 0.26 \\
\hline & $\begin{array}{l}\text { no autonomy } \\
\text { Kruskal-Wallis test }\end{array}$ & 50 & $\begin{array}{l}15.0 \\
p=0.074\end{array}$ & 42 & $\begin{array}{l}0.22 \\
p=0.027\end{array}$ \\
\hline \multirow{3}{*}{$\begin{array}{l}\text { Working } \\
\text { from home }\end{array}$} & never & 188 & 19.0 & 159 & 0.24 \\
\hline & sometimes & 98 & 25.1 & 88 & 0.29 \\
\hline & $\begin{array}{l}\text { at least once a week } \\
\text { Kruskal-Wallis test }\end{array}$ & 41 & $\begin{array}{l}39.4 \\
p=0.025\end{array}$ & 37 & $\begin{array}{l}0.49 \\
p=0.000\end{array}$ \\
\hline \multicolumn{6}{|c|}{ Sociodemographic factors } \\
\hline \multirow[t]{3}{*}{ Gender } & male & 202 & 25.6 & 176 & 0.33 \\
\hline & female & 169 & 20.3 & 141 & 0.24 \\
\hline & Mann-Whitney test & & $p=0.509$ & & $p=0.014$ \\
\hline \multirow{6}{*}{$\begin{array}{l}\text { Urbanization } \\
\text { degree }\end{array}$} & $<500$ addresses $/ \mathrm{km}^{2}$ & 90 & 20.8 & 78 & 0.28 \\
\hline & $500-1000$ addresses $/ \mathrm{km}^{2}$ & 64 & 22.1 & 60 & 0.22 \\
\hline & $1001-1500$ addresses $/ \mathrm{km}^{2}$ & 75 & 25.3 & 65 & 0.35 \\
\hline & $1501-2500$ addresses $/ \mathrm{km}^{2}$ & 48 & 18.9 & 35 & 0.35 \\
\hline & $>2500$ addresses $/ \mathrm{km}^{2}$ & 63 & 31.4 & 56 & 0.24 \\
\hline & Kruskal-Wallis test & & $p=0.495$ & & $p=0.043$ \\
\hline Total & & & 23.2 & & 0.29 \\
\hline
\end{tabular}

\subsection{Spatial configuration of fragments}

From subsection 5.1 we know that most of our respondents undertake paid work at a small number of locations. This has at least two ramifications for our analysis. The number of respondents for whom the area index $(A)$, cluster index $(R)$ and shape index $(\tau)$ and to a lesser degree the distance $(D)$ and orientation index $(\theta)$ can be calculated is rather limited. Additionally, the results for the orientation index in particular will be sensitive to the number of locations where paid work is undertaken $(L)$. Therefore, the results for the orientation index are given separately for $L=2$ and $L \geqslant 3$ (see table 7).

The first conclusion to be drawn from table 7 is that there are very few statistically significant differences $(p<0.10)$ in the spatial configuration of fragments according to ICT ownership and use, employment situation, and sociodemographic background. For the global dispersion measures, $A$ and $D$, there are three significant relations. Among the respondents who perform paid work at two locations, those possessing a PDA 
Table 7. Descriptive statistics for the spatial configuration of fragments, by number of locations (number of observations in parentheses).

\begin{tabular}{|c|c|c|c|c|c|c|c|}
\hline & & \multirow{2}{*}{$\begin{array}{l}\text { Area index } \\
(A) L \geqslant 3 \\
\text { (mean) }\end{array}$} & \multirow{2}{*}{$\begin{array}{l}\text { Cluster index } \\
(R) L \geqslant 3 \\
\text { (mean) }\end{array}$} & \multirow{2}{*}{$\begin{array}{l}\text { Distance } \\
(D) L=2 \\
\text { (mean) }\end{array}$} & \multicolumn{2}{|c|}{ Orientation index $(\theta)$} & \multirow{2}{*}{$\begin{array}{l}\text { Shape index } \\
(\tau) L \geqslant 3 \\
\text { (mean) }\end{array}$} \\
\hline & & & & & $L=2$ (mean) & $L \geqslant 3$ (mean) & \\
\hline \multicolumn{8}{|l|}{ ICT ownership and use } \\
\hline \multirow[t]{3}{*}{ Possession of $\mathrm{PDA}^{\mathrm{a}}$} & yes & 60.3 & 2.08 & $19.9(11)$ & $68.2(11)$ & $63.9(4)$ & 0.28 \\
\hline & no & $139.9(25)$ & $1.92(25)$ & $10.7(89)$ & $8.9(89)$ & $37.5(25)$ & $0.45(25)$ \\
\hline & statistical test & $p=0.527$ & $p=0.527$ & $p=0.049$ & $p=0.055$ & $p=0.027$ & $p=0.569$ \\
\hline \multirow[t]{3}{*}{ Possession of laptop } & yes & $145.1(7)$ & $1.85(7)$ & $12.8(28)$ & $1.5(28)$ & 51.9 & $0.37(7)$ \\
\hline & no & $123.8(22)$ & $1.97(22)$ & $11.3(72)$ & $7.9(72)$ & $37.7(22)$ & $0.44(22)$ \\
\hline & statistical test & $p=0.799$ & $p=0.460$ & $p=0.641$ & $p=0.640$ & $p=0.154$ & $p=0.799$ \\
\hline \multirow[t]{4}{*}{ General Internet use } & $<2$ hours per week & $79.7(7)$ & 2.14 (7) & $7.6(23)$ & $179.9(23)$ & $52.4(7)$ & 0.29 (7) \\
\hline & $2-5$ hours per week & $156.5(6)$ & $1.94(6)$ & $13.2(21)$ & $176.4(21)$ & $29.3(6)$ & $0.51(6)$ \\
\hline & $>5$ hours per week & $112.1(9)$ & $1.69(9)$ & $14.1(32)$ & $18.7(32)$ & $44.6(9)$ & $0.39(9)$ \\
\hline & statisical test & $p=0.844$ & $p=0.159$ & $p=0.296$ & $p=0.250$ & $p=0.363$ & $p=0.563$ \\
\hline \multicolumn{8}{|l|}{ Employment situation } \\
\hline \multirow{7}{*}{ Occupation type } & manager & $47.0(6)$ & $1.73(6)$ & $12.6(11)$ & $14.1(11)$ & $30.1(6)$ & $0.37(6)$ \\
\hline & high professional & $163.9(21)$ & $2.02(21)$ & $14.6(46)$ & $3.3(46)$ & $46.5(21)$ & $0.39(21)$ \\
\hline & low professional & $8.2(2)$ & $1.73(2)$ & $8.1(30)$ & $1.8(30)$ & $16.3(2)$ & 0.99 (2) \\
\hline & clerical staff & & & $8.9(6)$ & $172.1(6)$ & & \\
\hline & service worker & & & $6.3(3)$ & 35.9 (3) & & \\
\hline & skilled worker & & & $8.9(2)$ & $48.4(2)$ & & \\
\hline & statistical test & $p=0.269$ & $p=0.163$ & $p=0.633$ & $p=0.774$ & $p=0.108$ & $p=0.153$ \\
\hline Employment time & complete autonomy & $158.1(10)$ & $1.81(10)$ & $15.4(22)$ & 15.5 & $48.9(10)$ & $0.28(10)$ \\
\hline \multirow{3}{*}{ autonomy } & partial autonomy & 136.1 (11) & 1.97 (11) & $10.5(45)$ & $4.0(45)$ & 34.9 (11) & 0.53 (11) \\
\hline & no autonomy & $65.9(3)$ & $1.89(3)$ & $6.8(8)$ & $0.1(8)$ & 48.0 & 0.51 \\
\hline & statistical test & $p=0.803$ & $p=0.678$ & $p=0.463$ & $p=0.767$ & $p=0.402$ & $p=0.370$ \\
\hline \multirow[t]{4}{*}{ Working from home } & never & $103.4(8)$ & $1.87(8)$ & 7.4 & $179.8(43)$ & $42.7(8)$ & $0.45(8)$ \\
\hline & sometimes & $40.4(13)$ & $1.86(13)$ & $17.4(24)$ & $10.0(24)$ & $40.5(13)$ & $0.43(13)$ \\
\hline & at least once a week & $129.2(5)$ & $2.11(5)$ & $12.1(19)$ & $6.6(19)$ & $52.3(5)$ & $0.30(5)$ \\
\hline & statistical test & $p=0.028$ & $p=0.302$ & $p=0.046$ & $p=0.807$ & $p=0.472$ & $p=0.975$ \\
\hline \multicolumn{8}{|c|}{ Sociodemographic factors } \\
\hline \multirow[t]{3}{*}{ Gender } & male & $144.4(17)$ & $1.82(17)$ & $15.4(55)$ & $11.4(55)$ & $41.0(17)$ & $0.39(17)$ \\
\hline & female & 107.1 (12) & $2.11(12)$ & $7.3(45)$ & $177.9(45)$ & $41.2(12)$ & $0.46(12)$ \\
\hline & statistical test & $p=0.598$ & $p=0.033$ & $p=0.006$ & $p=0.199$ & $p=0.982$ & $p=0.535$ \\
\hline \multirow{6}{*}{ Urbanization degree } & $<500$ addresses $/ \mathrm{km}^{2}$ & $123.9(6)$ & $2.00(6)$ & $14.5(19)$ & $11.2(19)$ & $46.1(6)$ & $0.46(6)$ \\
\hline & $500-1000$ addresses $/ \mathrm{km}^{2}$ & $245.0(3)$ & $1.53(3)$ & $8.5(21)$ & $175.5(21)$ & $17.7(3)$ & $0.42(3)$ \\
\hline & $1001-1500$ addresses $/ \mathrm{km}^{2}$ & $194.4(8)$ & $1.84(8)$ & $12.5(26)$ & $12.2(26)$ & $43.4(8)$ & $0.32(8)$ \\
\hline & $1501-2500$ addresses $/ \mathrm{km}^{2}$ & $76.3(3)$ & $1.75(3)$ & $12.7(9)$ & $171.3(9)$ & $38.7(3)$ & $0.52(3)$ \\
\hline & $>2500$ addresses $/ \mathrm{km}^{2}$ & $56.1(6)$ & $2.12(6)$ & $11.1(14)$ & $13.0(14)$ & $56.1(6)$ & $0.42(6)$ \\
\hline & statistical test & $p=0.647$ & $p=0.155$ & $p=0.845$ & $p=0.779$ & $p=0.508$ & $p=0.272$ \\
\hline \multicolumn{2}{|l|}{ Total } & 129.0 & 1.94 & 11.7 & 58.7 & 41.1 & 0.42 \\
\hline
\end{tabular}


and men tend to have greater distances between those locations than those without a PDA and women. Both results concur with our expectations. A statistically significant difference is also observed for the area index among those who never, sometimes, or at least once per week work from home. However, the relationship is nonsystematic, presumably due to the small number of respondents engaging in paid labor at three or more locations. With regard to the shape and orientation of the spatial configuration, there is only one factor significantly related to the orientation of the locations vis-à-vis the commute axis: for respondents with a PDA the spatial pattern of locations is more perpendicular to the commute axis than for those who do not own a PDA. For the shape index we find no statistically significant differences, which is at least in part a consequence of the small number of respondents conducting paid work at three or more locations.

Most of our spatial configuration measures become particularly informative as activity participation is distributed across a greater number of locations. Because of the very small number of days on which respondents engaged in paid labor at four or more different locations, we can only explore the behavior of our measures in a qualitative manner. Therefore, we have selected three people with different employment characteristics and visualized the spatial fragmentation of their work activities (see figure 5).

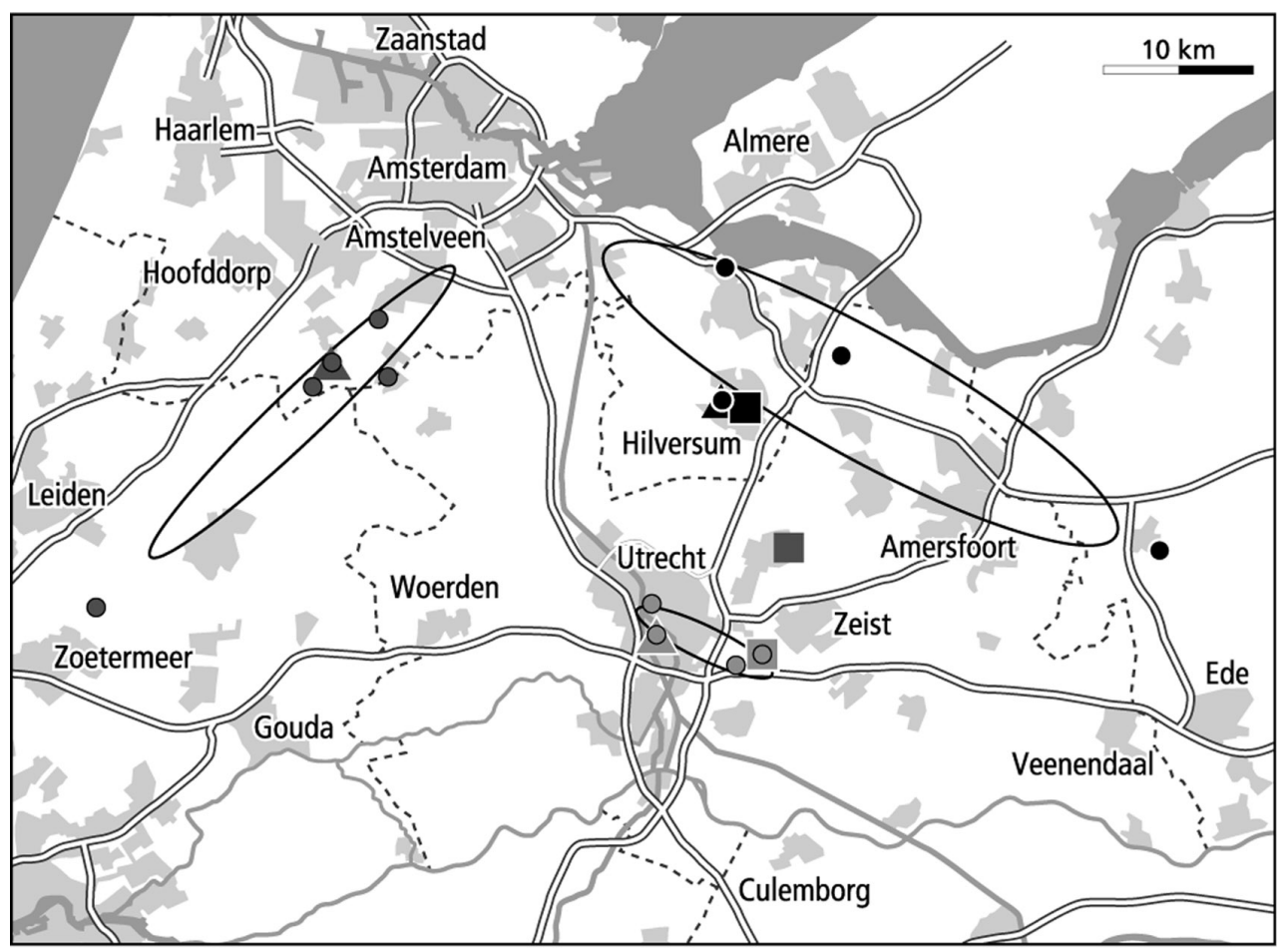

123 individual

Standard deviational ellipse

$\square \square \square$ home

$\triangle \Delta$ primary work location

- $\bigcirc$ other work location

Figure 5. Measures for the configuration of spatial fragmentation exemplified. 
With regard to the dispersion of fragments, figure 5 shows that individual 1 (managing director, horticulture) has the highest score on the area and cluster indices ( $\left.A=102.9 \mathrm{~km}^{2} ; R=2.04\right)$. Work locations for this individual are the most dispersed and are more evenly spread than those of the other two individuals. Individual 2 (manager, cleaning agency) works at five locations, which are less dispersed $\left(A=71.4 \mathrm{~km}^{2}\right)$. The pattern can be classified as globally clustered but with outliers $(R=1.66)$. Individual 3 (lawyer) has the lowest scores on the cluster and indices ( $A=19.3 \mathrm{~km}^{2} ; R=1.23$ ). Work locations for individual 3 are the most clustered, representing less spatial fragmentation with a pattern including multiple local clusters; one cluster is situated around the primary workplace and the other around home.

With respect to the shape of fragments, the set of locations for individual 1 tends to have an elliptical shape $(\tau=0.22)$ and this is especially true for individual 3 $(\tau=0.37)$, whose locations constitute an almost perfect ellipse. For individual 2 the shape is more linear $(\tau=0.17)$, primarily because of the location close to Zoetermeer (see figure 5). This indicates that the shape index is rather sensitive to outliers when the number of locations is rather limited and preferably should be used if there are multiple locations where episodes are conducted. Finally, in terms of the orientation of the set of locations vis-à-vis the commute (home-to-work) axis, there are marked differences between the three individuals. Locations for individual 1 are oriented rather strongly along the home-to-work axis $(\theta=118.3)$, which contrasts with individual $2(\theta=45.4)$ and especially individual $3(\theta=113.1)$. However, if the length of the home-to-work axis relative to the ellipse is too short, as it is for individual 1, there is no strongly structured ellipse. This suggests that the home-to-work axis is only a meaningful benchmark for the orientation of the spatial configuration of fragments if it is of considerable length.

\section{Conclusion}

As yet, the literature on activity fragmentation has been mainly conceptual and a clear framework for its measurement is lacking. In this study, we have developed a set of indicators for activity fragmentation and tested their performance empirically. These indicators have been based on the three dimensions of fragmentation proposed by Hubers et al and colleagues (2008): the number of fragments; the distribution of fragment sizes; and the configuration of the fragments. Although the empirical application of the measures in this study was restricted to paid work, the newly developed measures could be applied to study the fragmentation of any type of activity.

Overall, the study has shown that the newly developed measures were able to distinguish between less and more fragmented patterns of paid work and reveal systematic differences in the fragmentation of paid work according to ICT ownership and use, employment situation, and sociodemographic background. Summarizing the outcomes of the bivariate statistical analysis (table 8), we see that employment-related factors are most directly and most often associated with differences in the number of fragments, the distribution of fragment sizes, and the configuration of fragments. ICT ownership and use are associated more directly with temporal fragmentation than with spatial fragmentation, at least when the effects of confounding factors are not taken into consideration. The opposite seems to hold for the sociodemographic factor of gender, although we did not find women's paid work to be more fragmented than men's. This might suggest that fragmenting paid work is not a strategy women frequently employ to reconcile the competing demands on their space-time resources by employment and family life. However, these preliminary findings need to be explored with more advanced statistical methods in future research. 
Table 8. Summary of performance of fragmentation measures.

\begin{tabular}{|c|c|c|c|c|c|c|c|c|c|c|c|c|}
\hline & \multicolumn{2}{|c|}{ Number of fragments } & \multicolumn{2}{|c|}{ Distribution of fragment sizes } & \multicolumn{7}{|c|}{ Configuration of fragments } & \multirow[t]{2}{*}{ Total } \\
\hline & $E$ & $L$ & T-index & S-index & AID & ID-index & $A$ & $D$ & $R$ & $\theta$ & $\tau$ & \\
\hline ICT ownership and use & & & & & & & & & & & & 6 \\
\hline Possession of $\mathrm{PDA}^{\mathrm{a}}$ & $* *$ & & & & & * & ** & & & $* * * * *$ & & 4 \\
\hline Possession of laptop & & & ** & & & & & & & & & 1 \\
\hline General Internet use & $*$ & & & & & & & & & & & 1 \\
\hline Employment situation & & & & & & & & & & & & 15 \\
\hline Occupation type & $* *$ & $* *$ & & $* *$ & & & & & & & & 3 \\
\hline Employment time autonomy & ** & $* *$ & & $* *$ & * & ** & & & & & & 5 \\
\hline Working from home & $* *$ & $* *$ & & $* *$ & $* *$ & $* *$ & $* *$ & $* *$ & & & & 7 \\
\hline Sociodemographic factors & & & & & & & & & & & & 7 \\
\hline Gender & & * & & $*$ & & ** & $* *$ & & ** & & & 5 \\
\hline Urbanization degree & & $*$ & & & & $* *$ & & & & & & 2 \\
\hline Total & 5 & 5 & 1 & 4 & 2 & 5 & 3 & 1 & 1 & 1 & 0 & 28 \\
\hline
\end{tabular}


Whether or not the proposed measures adequately express fragmentation is difficult to ascertain. To date, fragmentation has been described primarily as a technologically induced development (activities becoming less temporally and spatially fixed due to the use of ICTs), and although the implications for activities have been the subject of speculation, they have not been verified empirically. However, since the proposed fragmentation measures reflect the hypothesized impacts of ICT ownership and use and employment situation on the fragmentation of paid work rather well, we believe that they are useful tools for the study of activity fragmentation. At the same time, the fact that we had to develop several measures to assess fragmentation indicates that it is a multidimensional concept with many different meanings. In many cases, researchers may wish to focus on a particular meaning of fragmentation depending on their study objectives; the application of fragmentation measures therefore requires an exact definition of the effects that are studied, leading to a choice of specific indicators. For instance, studying the impacts of ICT on work - life balance may require measures of the distribution of fragment sizes, such as the T-index, whereas the impacts of ICT on mobility would be better studied with measure of the spatial configuration of fragments.

Our study of activity fragmentation can be improved in at least two ways in future research: improvement of the measures of fragmentation and the collection of more appropriate data. As we have seen, at this stage many of the spatial fragmentation measures are of limited value because of the small number of respondents who engage in paid work at multiple locations. It is unclear, however, whether the spatial fragmentation of activities is not (yet) relevant or whether the limited results are the consequence of the relatively small number of respondents in our study. Future studies should therefore either use data from more respondents, or focus on time periods that exceed the diurnal cycle (eg the week or month), or both. Another way of increasing data availability would be to address multitasking, which would require asking respondents also about secondary activities (which was not requested in the diaries used for this analysis). By gathering information on possible secondary activities performed simultaneously, as is typical in time-use studies, a more complete representation of the activity under study would be obtained. What is more, other information should be collected on the purpose(s) served by a particular bundle of actions or subtask. Here we have used only five subtasks but it is evident that more-refined classification schemes could have been employed, which would also have resulted in the identification of more episodes. However, the use of more elaborate categorizations of subtasks should be traded against the extra respondent burden imposed on study participants. More experimentation is required in future studies as to what constitutes appropriate categorizations of subtasks for paid work and other activity types.

Regarding the measures of fragmentation, the current spatial fragmentation indicators are limited by their inability to include activities that are performed while being on the move, and the neglect of virtual activity locations. Because of the small number of respondents who apparently work while traveling, we expect that the suboptimal assessment of the spatial fragmentation of activities performed at nonstationary locations did not influence our results significantly. Nonetheless, activities-on-the-move should be considered differently in future studies. Data gathered via continuous GPS tracking of respondents' whereabouts, for example, could be analyzed using spatiotemporal GIS (Asakura and Hato, 2004; Miller, 2005; Shaw, 2000). An even more challenging task will be to incorporate nonstationary localities (eg a train) into measures of spatial fragmentation as developed in this paper. Additionally, information is also needed on the spatial characteristics of locations affected in some way by virtual activities. The notion of the contact set, which is defined as "the set of geographic locations that are contacted either physically or digitally for the purpose of initiating 
a physical or digital transfer" by an individual within a certain time span (Couclelis, 2000, page 348) is of relevance here. Even though one's physical action space might be confined to the municipality in which one lives, by trading products or exchanging information on the Internet with people from across the world, one's virtual or digital action space might encompass the entire world. That is not to say, however, that the contact-set size of Internet users automatically has a worldwide coverage since, for example, most of the products purchased on the Internet are bought from national retailers. The contact-set size thus forms the most comprehensive assessment of the spatial fragmentation of one's activities.

Further, while we have developed measures for temporal and spatial fragmentation separately in this study, it would be interesting to develop combined spatiotemporal indicators in future research. Miller's (2005) measurement theory for time geography might be a useful point of departure for the development of such indicators. Spatiotemporal indicators would allow us to analyze the temporal order in which different activity locations are visited and also to determine the relevance of activity locations for affording temporal fragmentation. These spatiotemporal measures may offer a more comprehensive characterization of the fragmentation of activities and might enhance the relevance and the cohesion between the fragmentation indices we have proposed.

We foresee several interesting applications of the proposed fragmentation measures in future research. Following the work of Hanson (1980) on spatial diversification, the first would be to study fragmentation on a longer time scale than the diurnal cycle. This would enable us to determine whether activity patterns that appear to be highly fragmented on the level of the day appear to be routinized when viewed over a longer period. The study of activity types other than paid work would also be of interest. Other promising research topics include the possible consequences of activity fragmentation for transportation and the built environment. Some studies have investigated whether the increased possibilities of working by means of ICTs have made train commuting more attractive (Lyons and Urry, 2005). Similarly, people who want to work from home might develop different demands for appropriate housing, since the house must enable working in a calm environment. A final issue concerns the way in which people experience the fragmentation of their activities. Although in general the increased opportunities ICTs offer to people to perform their activities wherever and whenever they want appear to be beneficial, activity fragmentation might also increase the complexity of activity scheduling and thus make it more burdensome. Thus, the question is how much fragmentation a person can handle before it changes from being a benefit to being a burden.

\section{References}

Asakura Y, Hato E, 2004, "Tracking survey for individual travel behavior using mobile communication instruments" Transportation Research Part C 12 273-291

Bachi R, 1962, "Standard distance measures and related methods for spatial analysis" Papers of Regional Science Association 1083 - 132

Buliung R, Kanaroglou P, 2006, "Urban form and household activity - travel behavior"Growth and Change $37172-199$

Castells M, 1996 The Rise of the Network Society (Blackwell, Oxford)

Couclelis H, 1998, "Editorial: the new field workers" Environment and Planning B: Planning and Design 25321 - 323

Couclelis H, 2000, "From sustainable transportation to sustainable accessibility: can we avoid a new tragedy of the commons?", in Information, Place and Cyberspace: Issues in Accessibility Eds D G Janelle, D C Hodge (Springer, Berlin) pp $341-356$

Couclelis H, 2003, "Housing and the new geography of accessibility in the information age" Open House International 28(4) 7 - 13 
Couclelis H, 2004, "Pizza over the internet: e-commerce, the fragmentation of activity and the tyranny of the region" Entrepreneurship and Regional Development $1641-54$

Damm D, 1979 Toward a Model of Activity Scheduling Behavior (MIT Press, Cambridge, MA)

Ebdon D, 1985 Statistics in Geography (Blackwell, Oxford)

Ettema D, Schwanen T, Timmermans H, 2007, "The effect of location, mobility and sociodemographic factors on task and time allocation of households" Transportation 34 89- 105

Furfey P H, 1972, "A note on Lefever's 'standard deviational ellipse'” American Journal of Sociology 33 94-98

Golob T F, 1998, "A model of household demand for activity participation and mobility", in Theoretical Foundations of Travel Choice Modeling Eds T Gärling, T Laitila, K Westin (Pergamon, Oxford) pp 365-398

González M C, Hidalgo C A, Barabási A-L, 2008, “Understanding individual human mobility patterns" Nature 435(7196) 779 - 782

Hanson S, 1980, "Spatial diversification and multipurpose travel: implications for choice theory" Geographical Analysis 12 245-257

Hanson S, 1982, "The determinants of daily travel-activity patterns: relative location and sociodemographic factors" Urban Geography 3 179-202

Hanson S, Huff J O, 1988, "Systematic variability in repetitious travel" Transportation 15111 - 135

Haythornthwaite C, Wellman B, 2002 The Internet in Everyday Life (Blackwell, Oxford)

Hjorthol R J, 2002, "The relation between daily travel and use of the home computer" Transportation Research Part A $36437-452$

Hubers C, Schwanen T, Dijst M, 2008, "ICT and temporal fragmentation of activities: an analytical framework and initial empirical findings" Tijdschrift voor Economische en Sociale Geografie $99528-546$

Huff J O, Hanson S, 1986, "Repetition and variability in urban travel” Geographical Analysis $1897-114$

Kakihara M, Sørensen C, 2004, "Mobile urban professionals in Tokyo: tales of locational, interactional and operational mobility" INFO: The Journal of Policy, Regulation and Strategy for Telecommunication, Information and Media 6(3) 180-187

Krygsman S, Dijst M, Arentze T, 2004, "Multimodal public transport: an analysis of travel time elements and interconnectivity ratio" Transport Policy $11265-275$

Kwan M-P, 2000, "Gender differences in space - time constraints" Area 32 145-156

Lefever D W, 1926, "Measuring geographic concentration by means of the standard deviational ellipse" American Journal of Sociology $3288-94$

Lenz B, Nobis C, 2007, "The changing allocation of activities in space and time by the use of ICT - 'fragmentation' as a new concept and empirical results" Transportation Research Part A 41 190-204

Lu X, Pas E I, 1999, "Socio-demographics, activity participation and travel behaviour" Transportation Research Part A $331-18$

Lyons G, Urry J, 2005, "Travel time use in the information age" Transportation Research Part A $39257-276$

Miller H J, 2005, "A measurement theory for time geography" Geographical Analysis 37 17-45

Nishii K, Kondo K, 1992, "Trip linkages of urban railway commuters under time-space constraints: some empirical observations" Transportation Research Part B 2633 - 44

Pas E I, 1984, "The effect of selected sociodemographic characteristics on daily travel-activity behaviour" Environment and Planning A 16571 - 581

Pendyala R M, Goulias K G, Kitamura R, 1991, "Impact of telecommuting on spatial and temporal patterns of household travel" Transportation $18383-409$

Rutledge D, 2003 Landscape Indices as Measures of the Effects of Fragmentation: Can Pattern Reflect Process? New Zealand Department of Conservation, Wellington

Saxena S, Mokhtarian P L, 1997, "The impact of telecommuting on the activity spaces of participants" Geographical Analysis 29124 - 144

Schwanen T, 2007, "Gender differences in chauffeuring trips among dual-earner families" The Professional Geographer 59447 - 462

Schwanen T, Dijst M, 2003, "Time windows in workers' activity patterns: empirical evidence from the Netherlands" Transportation $30261-283$

Shaw S, 2000, "Moving toward spatiotemporal GIS for transportation applications", in Proceedings of the 20th ESRI User Conference, http://gis.esri.com/library/userconf/proc00/ professional/papers/PAP205/p205.htm 
Tillema T, Dijst M, Schwanen T, 2010, "Face-to-face and electronic communications in maintaining social networks: the influence of geographical and relational distance and of information content" New Media and Society $12965-983$

van Wel R, Knijn T, 2007, "Transitional phase or a new balance?: working and caring by mothers with young children in the Netherlands" Journal of Family Issues $27633-651$ 
Conditions of use. This article may be downloaded from the E\&P website for personal research by members of subscribing organisations. This PDF may not be placed on any website (or other online distribution system) without permission of the publisher. 